\title{
AN ARCHAEOLOGICAL AND PALEONTOLOGICAL CHRONOLOGY FOR DAISY CAVE (CA-SMI-261), SAN MIGUEL ISLAND, CALIFORNIA
}

\author{
JON M. ERLANDSON, ${ }^{1}$ DOUGLAS J. KENNETT, ${ }^{2}$ B. LYNN INGRAM, ${ }^{3}$ DANIEL A. GUTHRIE, ${ }^{4}$ \\ DON P. MORRIS, ${ }^{5}$ MARK A. TVESKOV, ${ }^{1}$ G. JAMES WEST ${ }^{6}$ and PHILLIP L. WALKER ${ }^{2}$
}

\begin{abstract}
We provide detailed contextual information on $25{ }^{14} \mathrm{C}$ dates for unusually well-preserved archaeological and paleontological remains from Daisy Cave. Paleontological materials, including faunal and floral remains, have been recovered from deposits spanning roughly the past $16,000 \mathrm{yr}$, while archaeological materials date back to ca. 10,500 BP. Multidisciplinary investigations at the site provide a detailed record of environmental and cultural changes on San Miguel Island during this time period. This record includes evidence for the local or regional extinction of a number of animal species, as well as some of the earliest evidence for the human use of boats and other maritime activities in the Americas. Data from Daisy Cave contribute to a growing body of evidence that Paleoindians had adapted to a wide variety of New World environments prior to 10,000 BP. Analysis of shell-charcoal pairs, along with isotopic analysis of associated marine shells, supports the general validity of marine shell dating, but also provides evidence for temporal fluctuations in the reservoir effect within the Santa Barbara Channel region.
\end{abstract}

\section{INTRODUCTION}

Separated from the mainland for hundreds of thousands of years, California's Channel Islands provide some of the earliest evidence for fully developed maritime cultures in the New World and contain a fascinating record of biological evolution and extinctions along the California coast. Among the most important archaeological and paleontological localities on the Channel Islands is Daisy Cave (archaeological site CA-SMI-261), a cave and rockshelter complex that contains stratified artifact- and fossil-bearing deposits dating from the terminal Pleistocene to the present. It is located on the northeast shore of San Miguel Island ca. $40 \mathrm{~km}$ off the Santa Barbara mainland coast (Fig. 1). At present, Daisy Cave is the earliest documented coastal shell midden in North America, occupied sequentially by Paleoindian, Paleocoastal, and more recent maritime peoples. Basketry and cordage remnants from the site date between ca. 8500 and 10,000 cal BP, doubling the documented antiquity of perishable woven technologies along the Pacific coast (Connolly, Erlandson and Norris 1995).

Five major archaeological components have been identified in the cave, with human occupations extending from ca. 12,000 to $700 \mathrm{cal}$ BP. The earliest component, in which small quantities of chipped stone artifacts and marine shells indicate a relatively ephemeral occupation, shows that early maritime peoples used boats to visit or colonize the islands during the terminal Pleistocene. Much more extensive Early Holocene deposits, dated between ca. 8500 and 10,000 cal BP, have produced a diverse archaeological assemblage that includes basketry and cordage, a variety of chipped stone tools, and artifacts made from bone and marine shell. During the Middle Holocene, human occupation of Daisy Cave appears to be marked only by a thin shell midden stratum dated to $c a$. $6700 \mathrm{cal} \mathrm{BP}$, but this component has produced a rich assemblage of culturally selected faunal remains. The Late Holocene was again marked by relatively intensive occupation; a diverse assemblage of woven artifacts, stone, bone, shell, and other artifacts has been recovered, including a unique "bead-maker's kit" (Rozaire 1978). Near the end of the occupational sequence, it appears that Chumash Indian people used the site primarily as a place to bury their dead.

\footnotetext{
${ }^{1}$ Department of Anthropology, University of Oregon, Eugene, Oregon 97403-1218 USA

${ }^{2}$ Department of Anthropology, University of California, Santa Barbara, California 93106 USA

${ }^{3}$ Department of Geography, University of California, Berkeley, California 94720 USA

${ }^{4}$ W. M. Keck Science Center, Claremont Colleges, Claremont, California 91711-5916 USA

${ }^{5}$ Channel Islands National Park, 1901 Spinnaker Dr., Ventura, California 93001 USA

${ }^{6}$ Bureau of Reclamation, Department of the Interior, Sacramento, California 95825-1898 USA
} 


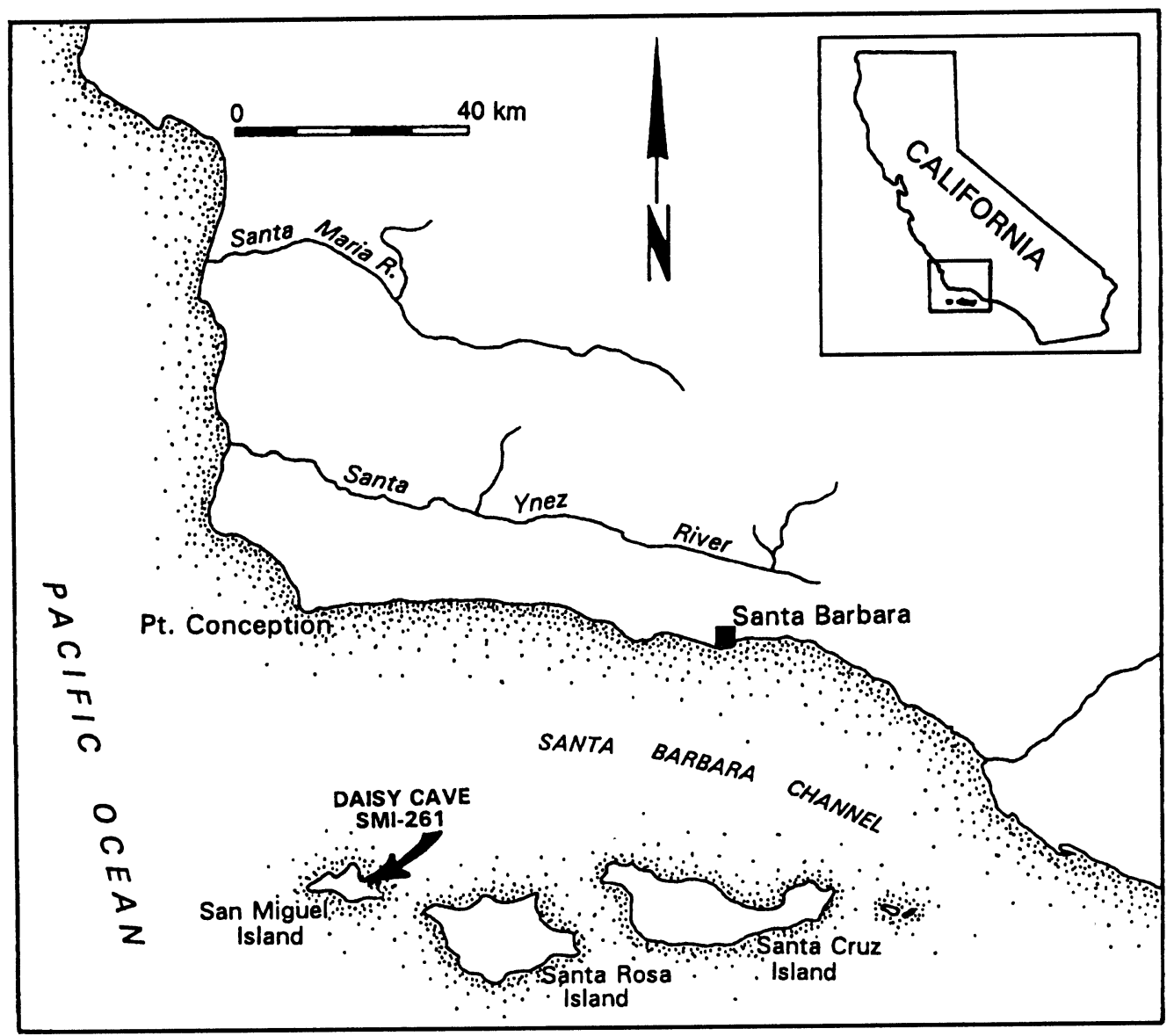

Fig. 1. Daisy Cave and the larger Santa Barbara Channel region

Faunal analyses of archaeological and paleontological specimens from the site have identified the remains of over 150 vertebrate and invertebrate species (Forgeng 1992), including several now extinct (Guthrie 1980; Walker 1980). This faunal assemblage results from the complex interaction of both cultural and biological (non-human) depositional processes. Recent research also shows that Daisy Cave contains a pollen record spanning much of the past 13,000 yr (West and Erlandson 1994), complementing a regional pollen record contained in varved sediments of the nearby Santa Barbara Basin (Heusser 1978). In short, Daisy Cave has produced a wealth of information the archaeology and paleoecology of the northern Channel Islands and the California coast (see also Connolly, Erlandson and Norris 1995; Erlandson 1991, 1993, 1994; Erlandson et al. 1996a, 1996b; Guthrie 1980, 1993; Kennett et al. 1996; Rozaire 1978, 1993; Walker 1980; Walker et al. 1978).

Until 1986, human occupation of Daisy Cave was thought to have begun only $c a .3000 \mathrm{yr}$ ago (Guthrie 1980; Rozaire 1978; Walker et al. 1978). Since 1986, when ${ }^{14} \mathrm{C}$ dating first demonstrated a much greater antiquity for the cave sequence, dating and other studies of the site or its contents have proceeded almost continuously. A comprehensive chronology for the cave deposits has not been published until now, however, and few details have been available on the context of individual ${ }^{14} \mathrm{C}$ samples. In this paper, we provide detailed contextual information on $25{ }^{14} \mathrm{C}$ dates for the archaeo- 
logical and paleontological deposits at Daisy Cave. These include dates on several matched pairs of marine shell and charcoal samples, which allow us to discuss methodological issues related to the comparability of marine and charcoal dates along the California coast and possible temporal fluctuations in the regional marine reservoir effect. In the sections that follow, we also discuss the general environmental and cultural patterns evident in the cave deposits, including vegetation changes in the site vicinity, evidence for the local or regional extinction of several animal species and general patterns of resource use by the human occupants of the cave. First, however, we provide background data on the structure of Daisy Cave, the history of research at the site and the methods employed in our study.

\section{DESCRIPTIVE BACKGROUND}

\section{Physical Setting}

San Miguel is the westernmost of the Northern Channel Islands, which contain an impoverished terrestrial flora and fauna compared to the adjacent California mainland. In contrast, the waters around the islands are nourished by upwelling and nutrient-rich currents that support a diverse and highly productive marine ecosystem. During the Last Glacial, the Northern Channel Islands were connected in a single island land mass known as Santarosae (Orr 1968). The ocean floor off Daisy Cave drops off rapidly, so the cave appears to have remained relatively close to the sea throughout the last $12,000 \mathrm{yr}$, even when sea levels were $25-50 \mathrm{~m}$ lower than at present. This sustained proximity to the sea partially explains the antiquity and extent of the archaeological deposits at the cave, since many Channel Island sites located along the current shoreline would have been several kilometers from the coast during the terminal Pleistocene.

Daisy Cave is located just above an isolated, rough and rocky stretch of shoreline on the northeast coast of San Miguel Island. The cave appears to have been formed during the Pleistocene by marine erosion associated with a high interglacial sea stand. Today, the cave is perched $c a .10 \mathrm{~m}$ above sea level immediately above the shoreline near the base of an ancient sea cliff of relatively erosion-resistant andesitic conglomerate. The site faces northward and is exposed to the full force of the northwesterly winds that buffet San Miguel Island much of the year (Johnson 1972: 63). The interior of Daisy Cave (Fig. 2), however, is one of the few places on the island where one can escape such winds. This shelter helps to explain the repeated and extensive use of the cave by humans, despite the lack of fresh water in the immediate vicinity.

Daisy Cave consists of a narrow fissure $c a .11 \mathrm{~m}$ deep and 1.5 to $3 \mathrm{~m}$ wide; an outer rockshelter $c a$. $4 \mathrm{~m} \times 5 \mathrm{~m}$ wide and a stratified shell midden deposit on the slope in front of the cave and shelter. Archaeological and paleontological deposits have been found in all three site areas. The cave itself is divided into three narrow chambers separated by two low crawl spaces. Today, a person can stand comfortably in the front and back chambers, but the middle chamber provides sitting room only. The archaeological deposits at Daisy Cave seem to have covered over $200 \mathrm{~m}^{2}$ at one time, but this extent has been reduced somewhat by coastal erosion.

\section{History of Excavation and Research}

Daisy Cave is situated within the historical territory of the Chumash Indians, among the most sociopolitically, economically and technologically complex hunter-gatherer cultures anywhere on earth (Arnold 1992; Moratto 1984: 118). The elaborate archaeological manifestations of Chumash society have attracted the attention of antiquarians, archaeologists, anthropologists and amateurs for over 125 yr. The earliest excavations of Daisy Cave probably occurred in the late 1800s and early 1900 s. 


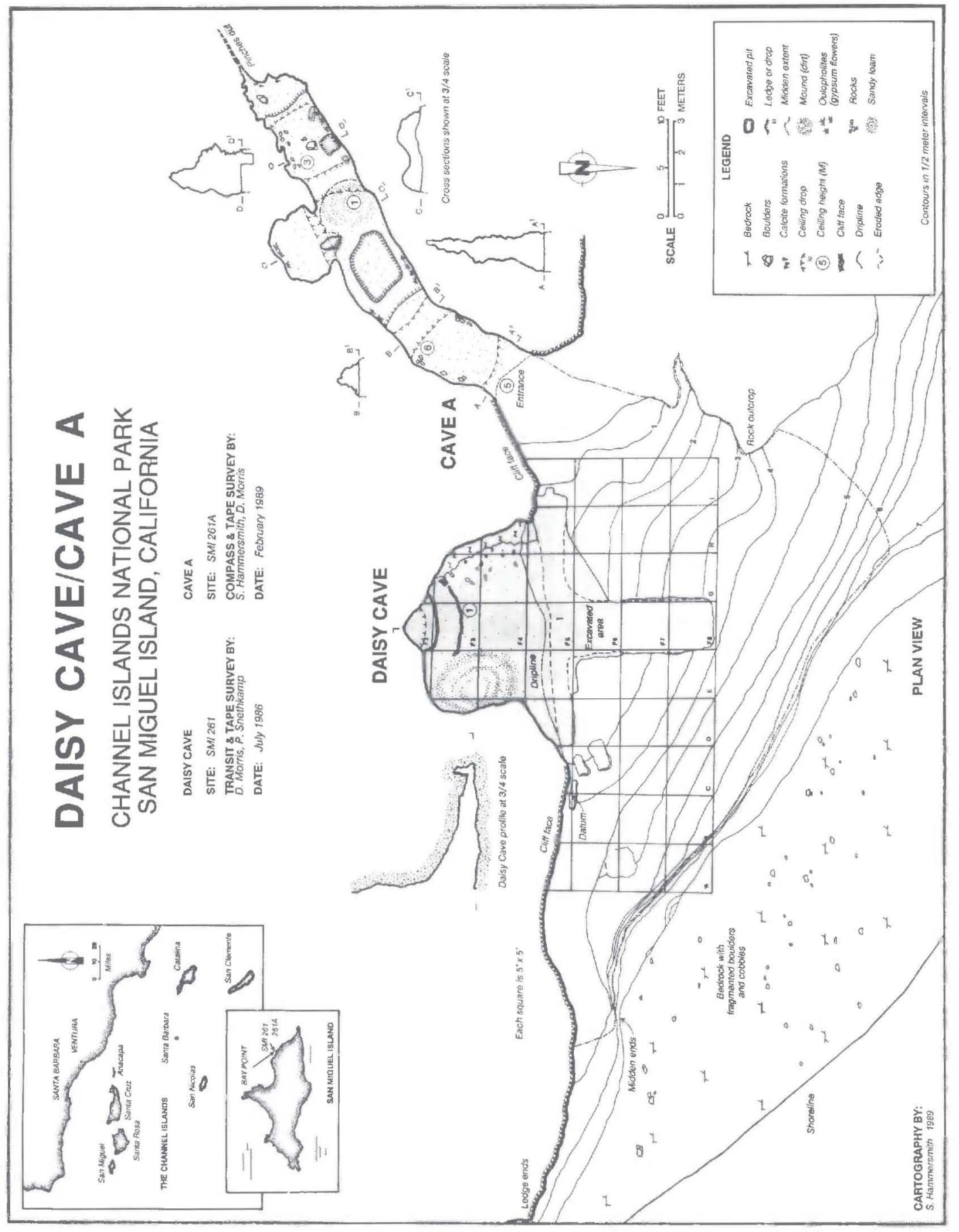

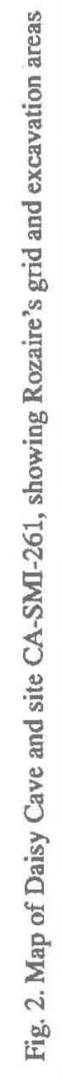


The diary of a rancher's wife describes an 1888 outing in which a human skull was dug from a cave at "Eagle's Cliff" (Daly 1990), a historical place name for the Daisy Cave area. Another probable early excavator was Ralph Glidden, an energetic antiquarian who ransacked numerous San Miguel Island archaeological sites in 1919, with financial support from the Heye Foundation. Heye's (1921) report of Glidden's San Miguel Island expedition depicts a cemetery excavated near Bay Point. Neither Heye nor Glidden (1919) described the physical setting of this locality, but circumstantial evidence strongly suggests that the site was Daisy Cave since later investigations found the remnants of a badly disturbed cemetery inside the cave (Rozaire 1978; Walker et al. 1978). Phil Orr (1950: 14) of the Santa Barbara Museum of Natural History probably also describes a visit to the site (which he called Hoffmann Cave), a place where "ancient Indians had been buried."

In 1967-1968, the first well-documented archaeological investigation at Daisy Cave was directed by Charles Rozaire of the Los Angeles County Museum of Natural History. Using methods typical of California archaeology at the time, Rozaire's team excavated $c a .20 \%$ of the archaeological deposits at Daisy Cave, including the whole interior of the rockshelter, a trench through the midden in front of the shelter and a test pit in the middle chamber of the cave. Rozaire (1978) recovered a diverse array of artifacts and faunal remains and collected the badly disturbed skeletal remains of at least 26 people who had once been buried in the cave. Each $5 \times 5$ foot $\left(1.52 \mathrm{~m}^{2}\right)$ test pit was excavated in arbitrary 6-inch $(15.2 \mathrm{~cm})$ levels oriented horizontally. Many of these appear to have crosscut the finely stratified cave sediments, especially in the deeper deposits in front of the cave and rockshelter, where the strata slope downward to the east and north. As a result, it is difficult to confidently associate much of this assemblage with anything other than very general time periods. Because 1/4-inch $(\sim 6 \mathrm{~mm})$ screen was used to sift most of the excavated sediments, small artifacts and faunal remains are underrepresented in the recovered assemblage. At the time, the chronology of the cave occupation was estimated strictly from temporally sensitive artifacts-rare in early Channel Islands assemblages-and Rozaire (1978) and Walker et al. (1978) concluded that the excavated strata spanned only the last $3000 \mathrm{yr}$.

The true antiquity of the cave deposits was not recognized until 1985-1986, when Guthrie, Morris and Snethkamp collected materials from the site surface and stratigraphic profiles, cleared and redocumented the strata exposed in Rozaire's trench walls, excavated two small test pits inside the cave and collected two column samples from the trench walls in front of the rockshelter. The test pits in the cave recovered little, but the columns-carefully excavated in natural stratigraphic levelsrecovered invaluable faunal and artifactual remains. Dating of shells from these columns first suggested a terminal Pleistocene age for the earliest human occupations at Daisy Cave and established the Pleistocene age of the underlying paleontological strata.

In 1989, Morris, S. Hammersmith and Erlandson finished mapping Daisy Cave and laid plans for additional site investigations. In 1991, the 1985-1986 collections were transferred to the University of Oregon for detailed analysis. In the summers of 1992, 1993, 1994 and 1996, Erlandson directed further investigations at Daisy Cave, designed to collect additional archaeological and paleontological samples, recover a sample of unique basketry and cordage identified in the Early Holocene levels at the site, explore the evidence for a terminal Pleistocene human occupation of the cave and extend the paleontological record further back into the Pleistocene. The 1992-1996 efforts completed the stratigraphically controlled excavation of three $50 \mathrm{~cm} \times 100 \mathrm{~cm}$ wide test units in the deposits outside the rockshelter and an exploratory sounding extending Rozaire's test pit inside the cave deeper into stratified sediments beneath the cave floor. 


\section{DATING METHODS}

The $25{ }^{14} \mathrm{C}$ samples described below were analyzed at two laboratories. Twelve marine shell samples and one charcoal sample were analyzed at Beta Analytic, Inc. (Beta) of Coral Gables, Florida, using conventional liquid scintillation techniques. Eleven small charcoal samples and one marine shell sample were analyzed at the Center for Accelerator Mass Spectrometry (CAMS) at the University of California's Lawrence Livermore National Laboratory.

At Beta Analytic, the external surfaces of the shell samples were etched in dilute $\mathrm{HCl}$ acid to remove portions of the shell most susceptible to contamination via weathering and exchange with the surrounding matrix. The shell samples submitted were unusually well preserved, however, with little or no evidence for weathering or contamination. After pretreatment, the remaining shell from each sample was dissolved in a second acid wash to produce carbon dioxide. The charcoal sample was crushed and dispersed in deionized water and submitted to successive $\mathrm{HCl}-\mathrm{NaOH}-\mathrm{HCl}$ washes to eliminate carbonates, remove mechanical contaminants and secondary organic acids, and neutralize the solution. According to correspondence from Beta Analytic, benzene synthesis and counting proceeded normally for all samples submitted. ${ }^{13} \mathrm{C} /{ }^{12} \mathrm{C}$ ratios were measured for each shell sample and ${ }^{14} \mathrm{C}$ ages were adjusted accordingly.

At the CAMS facility, small charcoal samples weighing 2 to $4 \mathrm{mg}$ were selected for dating from samples consisting mostly of carbonized twigs culled from flotation samples housed at the University of Oregon. Small twigs were selected to avoid the "old wood" effect (Schiffer 1986), a potentially significant problem on the Channel Islands where driftwood logs or wood from relict terminal Pleistocene forests may have been burned by the human occupants of the cave. Prior to dating, the charcoal samples were pretreated with alternating acid-base-acid rinses using $\mathrm{HCl}(1.0 \mathrm{~N})$ and $\mathrm{NaOH}(1.0 \mathrm{~N})$, with final rinses in acid to remove any absorbed $\mathrm{CO}_{2}$ and in deionized water to remove adhering organic acids or carbonate. The samples were dried and combusted at $850^{\circ} \mathrm{C}$ for $5 \mathrm{~h}$ in sealed quartz tubes to convert organic carbon to carbon dioxide. The evolved $\mathrm{CO}_{2}$ from each sample was converted to graphite using standard techniques (Vogel, Nelson and Southon 1987 ). ${ }^{14} \mathrm{C} /$ ${ }^{12} \mathrm{C}$ ratios were measured by AMS, as described elsewhere in detail (Davis et al. 1990). We assumed a ${ }^{13} \mathrm{C}$ value of -25 in calculating ${ }^{14} \mathrm{C} /{ }^{13} \mathrm{C}$ ratios and correcting for mass-dependent fractionation.

To effectively compare dates for marine shell and charcoal samples, all ${ }^{14} \mathrm{C}$ dates were calibrated via Stuiver and Reimer's (1993) CALIB 3.0.3 computer program (Table 1). These calibrated calendar dates were then used to construct a relatively high-resolution chronology for the finely stratified archaeological and paleontological deposits at Daisy Cave. Paired samples of marine shell and charcoal from the same stratigraphic levels were also used to examine the potential for temporal fluctuations in the intensity of marine upwelling and the regional reservoir effect $(\Delta R)$ in the Santa Barbara Channel area (Kennett et al. 1996).

\section{RADIOCARBON DATES FOR ARCHAEOLOGICAL AND PALEONTOLOGICAL SAMPLES}

\section{Late Holocene Series}

These samples are from two site areas: the upper strata excavated by Rozaire in the relatively shallow midden deposits inside the rockshelter; and from Stratum A, the uppermost of the deep midden deposits in front of the rockshelter (Fig. 3). Most of the sediments inside the rockshelter appear to have been stratigraphically superior to, or contemporary with, Stratum A. Artifacts found within the rockshelter sediments include a "bead-maker's kit" containing Purple Olive (Olivella biplicata) shell bead blanks, shell fishhook blanks, small chert bladelets and bladelet drills used in bead-mak- 
TABLE 1: A Radiocarbon Chronology for Daisy Cave (CA-SMI-261), San Miguel Island, California*

\begin{tabular}{|c|c|c|c|c|c|}
\hline $\begin{array}{l}\text { Provenience } \\
\text { (Unit/Stratum) }\end{array}$ & Lab number & Material dated & $\begin{array}{l}\text { Uncorrected } \\
{ }^{14} \mathrm{C} \text { age }\end{array}$ & $\begin{array}{l}{ }^{13} \mathrm{C} /{ }^{12} \mathrm{C} \\
\text { adjusted }\end{array}$ & $\begin{array}{l}\text { Calendar age } \\
\text { range (cal BP) }\end{array}$ \\
\hline Unit G3, $15-30 \mathrm{~cm}$ & Beta-56911 & Giant chiton shell & $1050 \pm 80$ & $1400 \pm 80$ & $780(700) 640$ \\
\hline Col. E-6, Str. A1 & CAMS-8864 & Charred twig & - & $3220 \pm 70$ & $3360(3430) 3480$ \\
\hline Col. E-6, Str. A1 & Beta-49997 & Black abalone shell & $3070 \pm 80$ & $3510 \pm 80$ & $2970(3110) 3230$ \\
\hline Col. E-6, Str. A3 & CAMS-9095 & Charred twig & - & $3110 \pm 60$ & $3220(3350) 3380$ \\
\hline Col. E-6, Str. A3 & Beta-15619 & Red abalone shell & $2990 \pm 90$ & $3430 \pm 90$ & $2860(2980) 3140$ \\
\hline Col. E-6, Str. C & CAMS-8862 & Charred twig & - & $6000 \pm 70$ & $6750(6830) 6900$ \\
\hline Col. E-6, Str. C & Beta- 15620 & Black abalone shell & $5940 \pm 110$ & $6380 \pm 110$ & $6440(6600) 6720$ \\
\hline Col. E-6, Str. C & Beta-52359 & CA mussel shell & $6090 \pm 80$ & $6500 \pm 80$ & $6630(6720) 6820$ \\
\hline Col. E-6, Str. E1 & CAMS-8866 & Charred twig & -- & $7810 \pm 60$ & $8440(8550) 8580$ \\
\hline Col. E-6, Str. E1 & Beta-15621 & Black abalone shell & $8030 \pm 100$ & $8460 \pm 100$ & $8530(8680) 8930$ \\
\hline Col. I-5, Str. J & Beta-19871 & CA mussel shell & $8290 \pm 200$ & $8700 \pm 200$ & $8730(9010) 9340$ \\
\hline Col. E-6, Str. E4 & CAMS-8865 & Charred twig & - & $8040 \pm 60$ & $8730(8960) 8990$ \\
\hline Col. E-6, Str. E4 & Beta-15622 & Black abalone shell & $8270 \pm 120$ & $8730 \pm 120$ & $8950(9080) 9260$ \\
\hline Col. E-6, Str. F1 & CAMS-8867 & Charred twig & - & $8600 \pm 60$ & $9490(9520) 9550$ \\
\hline Col. E-6, Str. F1 & Beta-15623 & CA mussel shell & $8470 \pm 120$ & $8900 \pm 120$ & $9170(9330) 9430$ \\
\hline Col. E-6, Str. F3 & CAMS-8863 & Charred twig & - & $8810 \pm 80$ & 9650 (9770 9910 \\
\hline Cave A, 26-30 cm & CAMS-12456 & CA mussel shell & - & $9110 \pm 90$ & 9420 (9480) 9580 \\
\hline Cave A, 26-30 cm & CAMS-14366 & Charred twig & - & $9180 \pm 60$ & $10,040(10,060) 10,280$ \\
\hline Col. E-6, Str. F3 & Beta-49948 & CA mussel shell & $8940 \pm 90$ & $9360 \pm 90$ & 9650 (9830) 9900 \\
\hline Col. E-6, Str. G & Beta-52360 & Black turban shell & $10,180 \pm 70$ & $10,600 \pm 70$ & $11,250(11,460) 11,670$ \\
\hline Col. E-6, Str. G & Beta-14660 & Red abalone shell & $10,260 \pm 90$ & $10,700 \pm 90$ & $11,440(11,670) 11,940$ \\
\hline Col. E-6, Str. G & CAMS-9094 & Wood charcoal & -- & $10,390 \pm 130$ & $12,060(12,290) 12,460$ \\
\hline Col. E-6, Str. I & CAMS-9096 & Wood charcoal & -- & $11,180 \pm 130$ & $12,950(13,090) 13,230$ \\
\hline Col. E-6, Str. J & CAMS-14369 & Charred twig & -- & $11,700 \pm 70$ & $13,520(13,640) 13,770$ \\
\hline Cave A, $150-60 \mathrm{~cm}$ & Beta-77070 & Wood charcoal & $15,780 \pm 120$ & $15,780 \pm 120$ & $18,530(18,670) 18,810$ \\
\hline
\end{tabular}

*Beta Analytic dates are based on conventional (LSC) radiocarbon dating; CAMS dates are based on accelerator mass spectrometry. CA mussel = California mussel (Mytilus californianus). Rounded calendar ages include midpoint (in parentheses) and age range at one sigma, calibration via Stuiver and Reimer's (1993) CALIB 3.0.3 program.

ing, the remnants of a woven basketry bag and other artifacts (Rozaire 1993). These rockshelter sediments also produced numerous other woven sea grass (Phyllospadix sp.) items, including cordage, rope and a textile fragment (Rozaire 1978). Tarring pebbles, heated and swirled inside baskets with bitumen to make them watertight, were also found primarily in the upper levels. The Late Holocene levels were rich in faunal remains, including sea mammals (cetaceans, pinnipeds and sea otters), a diverse array of birds, marine fish and shellfish (mussels, abalones, turbans, sea urchins, etc.) and limited amounts of terrestrial mammal (mice, shrew, bat, island fox and skunk). Stratum A, once one of the major occupational strata on the slope in front of the rockshelter, has been highly eroded due to sheet wash and other processes. Recent small-scale excavations in the remnants of this deposit have produced numerous faunal remains and expedient chipped stone artifacts, but relatively few formal tools or other artifacts.

Beta-56911. Unit G-3, 15-30 cm

$1400 \pm 80$

Giant chiton (Cryptochiton stelleri) shell fragment, $15.6 \mathrm{~g}$, from Rozaire's test pit excavated inside the rockshelter at Daisy Cave. Collected 1967-1968 by LACMNH archaeologists, submitted 1992 by Erlandson to estimate the age of the most recent human occupation of Daisy Cave.

Comment (J.E.): this shell sample came from the same unit and general level that produced the "bead-maker's kit." Similar caches have been found in Northern Channel Islands sites dating to the last 1000 to $2000 \mathrm{yr}$ (e.g., Orr 1968). Beta-56911, with a calibrated midpoint equal to $c a .700 \mathrm{cal} \mathrm{BP}$, 


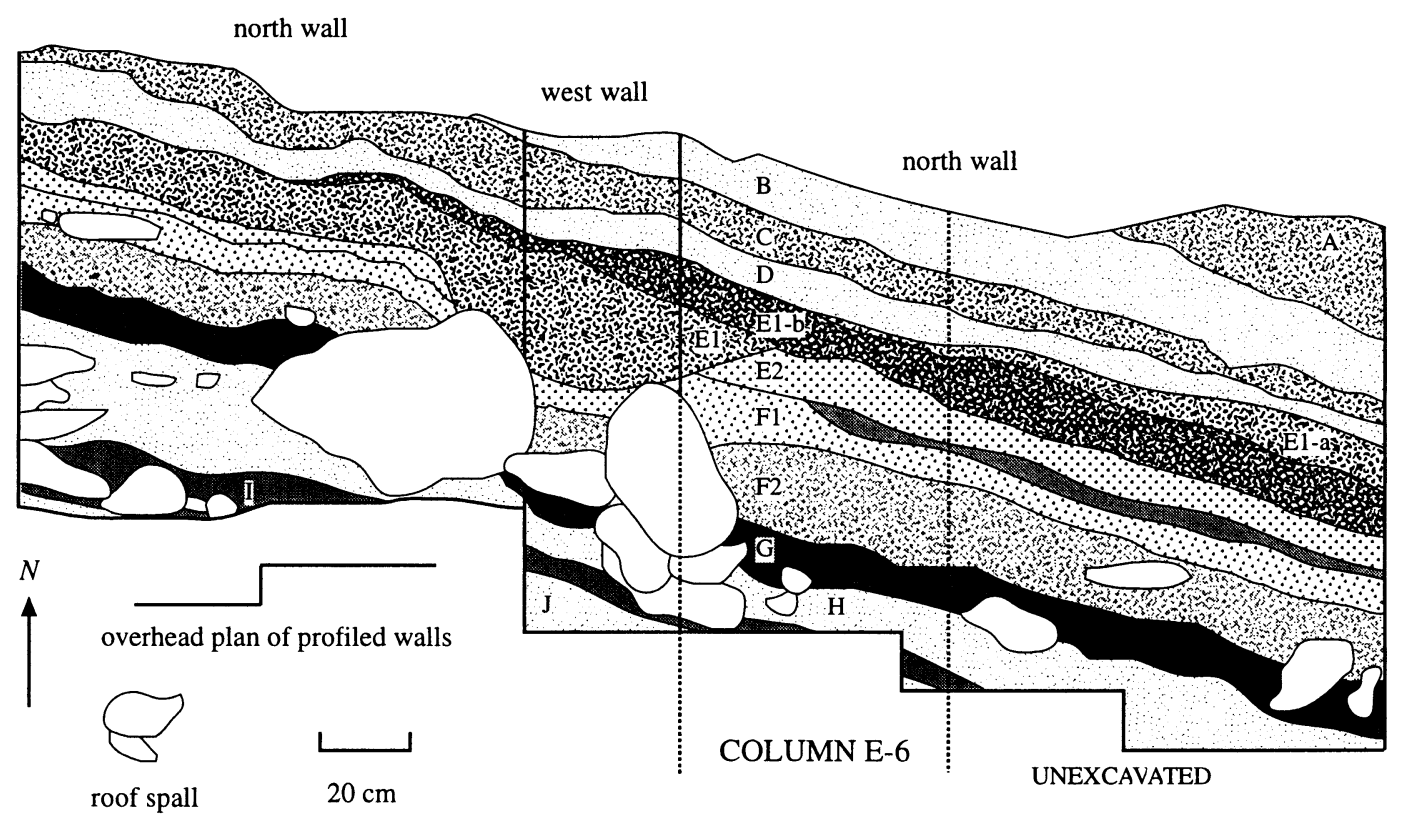

Fig. 3. Stratigraphy of archaeological and paleontological deposits along the dripline of the Daisy Cave rockshelter

is consistent with other data on the development of craft specialization in bladelet and bead production (Arnold 1987, 1992).

CAMS-9095. Column E-6, Stratum A3

$3110 \pm 60$

A small burned twig fragment from near the base of Stratum A, this sample comes from the same $10-12 \mathrm{~cm}$ thick stratum as marine shell sample Beta-15619. Collected 1985 by Guthrie and P. Snethkamp, submitted 1993 by Erlandson and Kennett to test comparability of marine shell and charcoal dates from cave strata.

Comment (J.E./D.K./L.I.): calibration of this date suggests that Stratum A may have begun to accumulate $c a .3400 \mathrm{cal}$ BP. Generally, the shell and charcoal dates are quite similar given the lack of precise spatial association, but the calibrated midpoint for the charcoal date is unexpectedly older $(+370$ yr) than the associated shell date (Beta-15619). Since an "old wood" problem should not affect this small twig, the difference may be due to other factors (see CAMS-8864).

CAMS-8864. Column E-6, Stratum A1

$3220 \pm 70$

A small burned twig from the upper part of Stratum A, this sample came from the same 4-6 cm thick stratum as marine shell sample Beta-49997. Collected 1985 by Guthrie and Snethkamp, submitted 1993 by Erlandson and Kennett to test the comparability of shell and charcoal dates and help refine the chronology for the human use of Daisy Cave.

Comment (J.E./D.K./L.I.): once again, shell and charcoal dates generally correspond, but the calibrated midpoint for this date is considerably older $(+320 \mathrm{yr})$ than expected. Consistent variation between the two shell/charcoal "pairs" from Stratum A suggests that differences between the shell and charcoal dates may be due to temporal fluctuations in the intensity of marine upwelling and the reservoir effect (see Kennett et al. 1996). 
Beta-15619. Column E-6, Stratum A3

$3430 \pm 90$

Red abalone (Haliotis rufescens) shell, $82 \mathrm{~g}$, from $25 \mathrm{~cm}$ below surface and near the base of Stratum A. Collected 1985 by Guthrie and Snethkamp, submitted 1986 by Guthrie to establish the age of archaeological and paleontological strata in the upper part of the stratigraphic profile outside the rockshelter.

Comment (J.E./D.G.): this date first showed that the dense 30-cm-thick shell midden stratum capping the sequence in front of the rockshelter began accumulating $c a .3000 \mathrm{cal} \mathrm{BP}$, roughly the age once estimated for the entire archaeological sequence at Daisy Cave.

Beta-49997. Column E-6, Stratum A1

Black abalone (Haliotis cracherodii) shell, $24.1 \mathrm{~g}$, from upper 4-6 cm of Stratum A, the uppermost stratum identified outside the rockshelter in 1985-1986. Collected 1985 by Guthrie and Snethkamp, submitted 1991 by Erlandson and Morris.

Comment (J.E.): By 1992, the loose Stratum A sediments had been removed almost completely by sheet wash erosion. This date, slightly younger than those from the overlying samples, shows a mild stratigraphic reversal. The two shell dates from Stratum A overlap at only one sigma, however, so this variation may be insignificant.

General Comments: The four dates that bracket Stratum A outside the rockshelter suggest that this component may have accumulated relatively rapidly, possibly during a single occupation of the site beginning ca. $3200 \pm 200 \mathrm{cal} \mathrm{BP}$. The complex and finely stratified shell midden deposits once present inside the rockshelter suggest that Daisy Cave was occupied repeatedly during the Late Holocene, however, with additional refuse deposited around $700 \mathrm{cal}$ BP. At some point, probably during the past $1000 \mathrm{yr}$, the cave itself seems to have been used primarily as a Chumash burial place.

\section{Middle Holocene Series}

Currently, a Middle Holocene human occupation of Daisy Cave is represented only in Stratum C, a $5-10-\mathrm{cm}$-thick shell midden identified in the deep midden deposits outside the rockshelter. However, the Stratum C cultural component may also have formed the base of the cultural deposits that Rozaire (1978) identified inside the rockshelter. After calibration, three dates for the occupation of Stratum C are highly consistent, averaging ca. $6720 \pm 150 \mathrm{cal} \mathrm{BP}$. Despite the relatively high density of archaeological materials in Stratum C, the thin nature of the deposits suggests that occupation of the site at this time was relatively brief. Due to the small volume of stratigraphically excavated sediments, relatively few artifacts can be confidently associated with this component. These include a few expedient flake tools, chipped stone debitage, a battered cobble hammerstone, a spire-ground Olivella bead, a fragment of worked bone and an abalone dish containing red ochre. The faunal assemblage is dominated by California mussel (Mytilus californianus) shells, but sea mammal, fish, bird and other vertebrate remains are also present.

The stratigraphy outside the rockshelter suggests that there was no substantial human occupation of Daisy Cave for long periods before and after the deposition of Stratum C. Above and below this occupational stratum are thin yellowish cave soils (Strata B and D) that appear to be culturally sterile. The few archaeological materials found in Strata B and D probably come from the accumulation of sediments over the uneven surfaces of the underlying midden strata, the downward trampling of cultural materials during later site occupations, or the limited redeposition of archaeological materials from upslope. Stratum B appears to have gradually accumulated during the Middle Holocene, between $c a .6700$ and $3200 \mathrm{cal} \mathrm{BP}$. The upper portions of Stratum D also seem to have accumulated early in the Middle Holocene. Faunal remains are relatively scarce in these noncultural strata, and 
pollen analysis suggests that the vegetation in the site vicinity was dominated by modern taxa (West and Erlandson 1994).

CAMS-8862. Column E-6, Stratum C $6000 \pm 70$

Small charred twig from flotation sample excavated by Guthrie and Snethkamp in 1985. Submitted 1993 by Erlandson and Kennett to refine the chronology of shell midden deposits in Stratum C and check the correlation between shell and charcoal samples from this short-term occupation level.

Comment (J.E.): after calibration, the midpoint of this date is 110 and $230 \mathrm{yr}$ older than the midpoints for shell samples from the same stratum. All three dates overlap at two sigma, however, suggesting that this variation is not statistically significant.

Beta-15620. Column E-6, Stratum C

$6380 \pm 110$

Black abalone shell, $52 \mathrm{~g}$, from $44 \mathrm{~cm}$ below the surface of midden. Collected 1985 by Guthrie and Snethkamp, submitted 1986 by Guthrie to establish the basic chronology of archaeological and paleontological deposits at Daisy Cave.

Comment (J.E.): this date, one of the initial ${ }^{14} \mathrm{C}$ series for Daisy Cave, first established the antiquity of Stratum $\mathrm{C}$ and roughly doubled the known antiquity of human occupation of the site.

Beta-52359. Column E-6, Stratum C

$6500 \pm 80$

California mussel shell valve, $13.2 \mathrm{~g}$, collected 1985 by Guthrie and Snethkamp, submitted 1992 by Erlandson to confirm the veracity of earlier date for Stratum $\mathrm{C}$.

Comment (J.E.): analysis of second shell sample from Stratum C confirmed the antiquity of the layer and the Middle Holocene occupation of the cave.

\section{Early Holocene Series}

Early Holocene archaeological and paleontological deposits have been identified inside Cave A, just inside the dripline of the rockshelter, and on the slope outside the cave and rockshelter. Of these, the deposits outside the cave/rockshelter are the most extensive, where Strata E and F are up to $50 \mathrm{~cm}$ thick and cover an area of roughly $120 \mathrm{~m}^{2}$. Dated between $c a .8500$ and $9900 \mathrm{cal}$ BP, the Early Holocene archaeological deposits appear to have accumulated during repeated short-term occupations of the site. Nonetheless, the extent and density of the refuse deposits suggest that the most intensive use of the site dates to this time period. Inside the driplines of the cave and rockshelter, these early shell midden deposits are loose and unconsolidated, almost completely undisturbed, remarkably well preserved, and interspersed with deposits of seabird guano. On the slope outside the driplines, most midden constituents in the same strata are still relatively well preserved, but seabird guano has been dispersed by rain and slopewash, and the strata are strongly indurated.

Artifacts recovered from the Early Holocene strata include three fragments of basketry and hundreds of strands of cordage made from sea grass, Olivella beads made by removing the spire or apex from whole shells, expedient chipped stone tools and toolmaking debris, small bipointed bone fish gorges, occasional leaf-shaped bifacial points or knives, and rarer stone, bone or shell artifact types. The most remarkable of these are the woven artifacts, which include what may be remnants of the toeflaps from two children's sandals (Connolly, Erlandson and Norris 1995). The shells of California mussels, black turbans (Tegula funebralis) and black abalones dominate the faunal assemblage, but fish, sea mammal and bird remains are also present. 
CAMS-8866. Column E-6, Stratum E1

$7810 \pm 60$

Small charred twig fragment extracted from flotation sample recovered from the uppermost of the Early Holocene strata. Collected 1985 by Guthrie and Snethkamp, submitted 1993 by Erlandson and Kennett. After calibration, this is the youngest calendar date $(8550 \mathrm{cal} \mathrm{BP})$ available from the Early Holocene strata at Daisy Cave.

Comment (J.E.): this sample was submitted to test comparability of ${ }^{14} \mathrm{C}$ dates from marine shell and charcoal. Stratum E1 produced a fragment of twined basketry-one of the possible sandal fragments-and hundreds of fragments of sea grass cordage (Connolly, Erlandson and Norris 1995).

CAMS-8865. Column E-6, Stratum E4

$8040 \pm 60$

Small charred twig fragment from a flotation sample from the lowest level of Stratum E. Collected 1985 by Guthrie and Snethkamp, submitted 1993 by Erlandson and Kennett.

Comment (J.E.): sample was submitted to test the comparability of marine shell and charcoal dates and to further refine the site chronology. After calibration, this date overlaps at one sigma with a shell date (Beta-15622) from the same stratigraphic level.

Beta-15621. Column E-6, Stratum E1

$8460 \pm 100$

A single black abalone shell ( $52.5 \mathrm{~g}$ ) from $55 \mathrm{~cm}$ below surface and the uppermost level of Stratum E. Collected 1985 by Guthrie and Snethkamp, submitted 1986 by Guthrie.

Comment (J.E.): this date, from the initial ${ }^{14} \mathrm{C}$ series for the site, almost tripled the known antiquity of human occupation at Daisy Cave. After calibration, this date overlaps at one sigma with the date (CAMS-8866) for a charred twig from the same level.

CAMS-8867. Column E-6, Stratum F1

$8600 \pm 60$

Charred twig from a flotation sample collected 1985 by Guthrie and Snethkamp, submitted 1993 by Erlandson and Kennett to help refine the cave chronology and test comparability of marine shell and charcoal samples in close stratigraphic association.

Comment (J.E./D.K.): after calibration the two dates from Stratum F1 overlap at two sigma, but the younger shell sample may indicate that coastal upwelling was less intense at this time and that the regional reservoir effect was less pronounced than during historic times (Kennett et al. 1996).

Beta-19871. Column I-5, Stratum J

$8700 \pm 200$

California mussel shell $(19.3 \mathrm{~g}$ ) from 108-111 cm below surface near the base of dense shell midden level in column sample located ca. $6 \mathrm{~m}$ west and upslope of Column E-6. Collected 1985 by Morris, submitted 1987 by Guthrie and Snethkamp to establish the antiquity of shell midden deposit closer to the mouth of Cave A.

Comment (J.E.): Stratum J from this column bears no relationship to Stratum J in Column E-6. The strata in Column I-5 were partly disturbed, probably by runoff along the base of the cliff. This sample appears to correlate with midden deposits near the base of Stratum E (see Beta-15622) located downslope in Column E-6.

Beta-15622. Column E-6, Stratum E4 $8730 \pm 120$

Black abalone shell $(63.4 \mathrm{~g})$ from $75 \mathrm{~cm}$ below surface in the lowest level of Stratum E. Collected 1985 by Guthrie and Snethkamp, submitted 1986 by Guthrie to establish the antiquity of the early shell midden levels. 
Comment (J.E.): this date, from the initial ${ }^{14} \mathrm{C}$ series for the site, is consistent with stratigraphically overlying and underlying samples and established that much of the shell midden deposits outside Daisy Cave dated to the Early Holocene.

CAMS-8863. Column E-6, Stratum F3

$8810 \pm 80$

Small charred twig from lowest $7-8 \mathrm{~cm}$ of Stratum F, near the base of the dense shell midden deposits at Daisy Cave. Collected 1985 by Guthrie and Snethkamp, submitted 1993 by Erlandson and Kennett.

Comment (J.E.): this sample, from the same general midden level as Beta-49948, was submitted to confirm the cave chronology and compare paired marine shell and carbon samples to explore possible diachronic changes in coastal upwelling and its effects on the local reservoir effect. After calibration, the two samples are very similar, overlapping at one sigma.

Beta-15623. Column E-6, Stratum F1

$8900 \pm 120$

California mussel shell $(91.0 \mathrm{~g})$ from $80 \mathrm{~cm}$ below surface in the uppermost level of Stratum F, a relatively dense shell midden stratum containing numerous chipped stone artifacts. Collected 1985 by Guthrie and Snethkamp, submitted 1986 by Guthrie.

Comment (J.E.): this date, among the initial series for the site, clearly established the presence of maritime peoples on the Northern Channel Islands at $\mathrm{ca} .9300 \mathrm{cal} \mathrm{BP}$.

CAMS-12456. Cave A, Profile A, Stratum VIII/IX

$9110 \pm 90$

California mussel shell fragment from near base of shell midden exposed in sounding within the middle chamber of Cave A (Fig. 4). Shell, from a small bulk midden sample, collected 1993 from 26-30 cm below surface by Kennett and L. Haslouer, submitted 1994 by Erlandson and Kennett.

Comment (J.E.): this date suggests that the base of the shell midden inside Cave A also dates to the Early Holocene and is roughly contemporary with strata F2 and F3 outside the rockshelter. This is consistent with the presence of numerous fragments of sea grass cordage and abundant black turban shells, both common in synchronic levels outside the cave.

CAMS-14366. Cave A, Profile A, Stratum VIII/IX

$9180 \pm 60$

Small charred twig from shell midden lens exposed in sounding within the middle chamber of Cave A. Collected 1993 as part of shell/charcoal pair by Kennett and Haslouer, submitted 1994 by Erlandson and Kennett.

Comment (J.E.): after calibration, the midpoint of the date for this burned twig is almost $600 \mathrm{yr}$ older than the associated shell, suggesting that marine upwelling was less intense at this time, that the cave occupants burned some older debris inside the cave, or some combination of the two. Calibration of this date suggests that the base of the midden inside Cave A may have been deposited as much as 10,060 yr ago.

Beta-49948. Column E-6, Stratum F3

$9360 \pm 90$

Fragments of California mussel shell $(30 \mathrm{~g})$ from the lowest level of the dense shell midden strata. Collected 1985 by Guthrie and Snethkamp, submitted 1991 by Erlandson and Morris to establish the age of the first unequivocal evidence for human occupation at Daisy Cave.

Comment (J.E.): calibration of this date suggests that the base of shell midden Stratum F outside the rockshelter was deposited $c a$. $9900 \mathrm{cal} \mathrm{BP}$. 
$\mathrm{cm}$ below datum

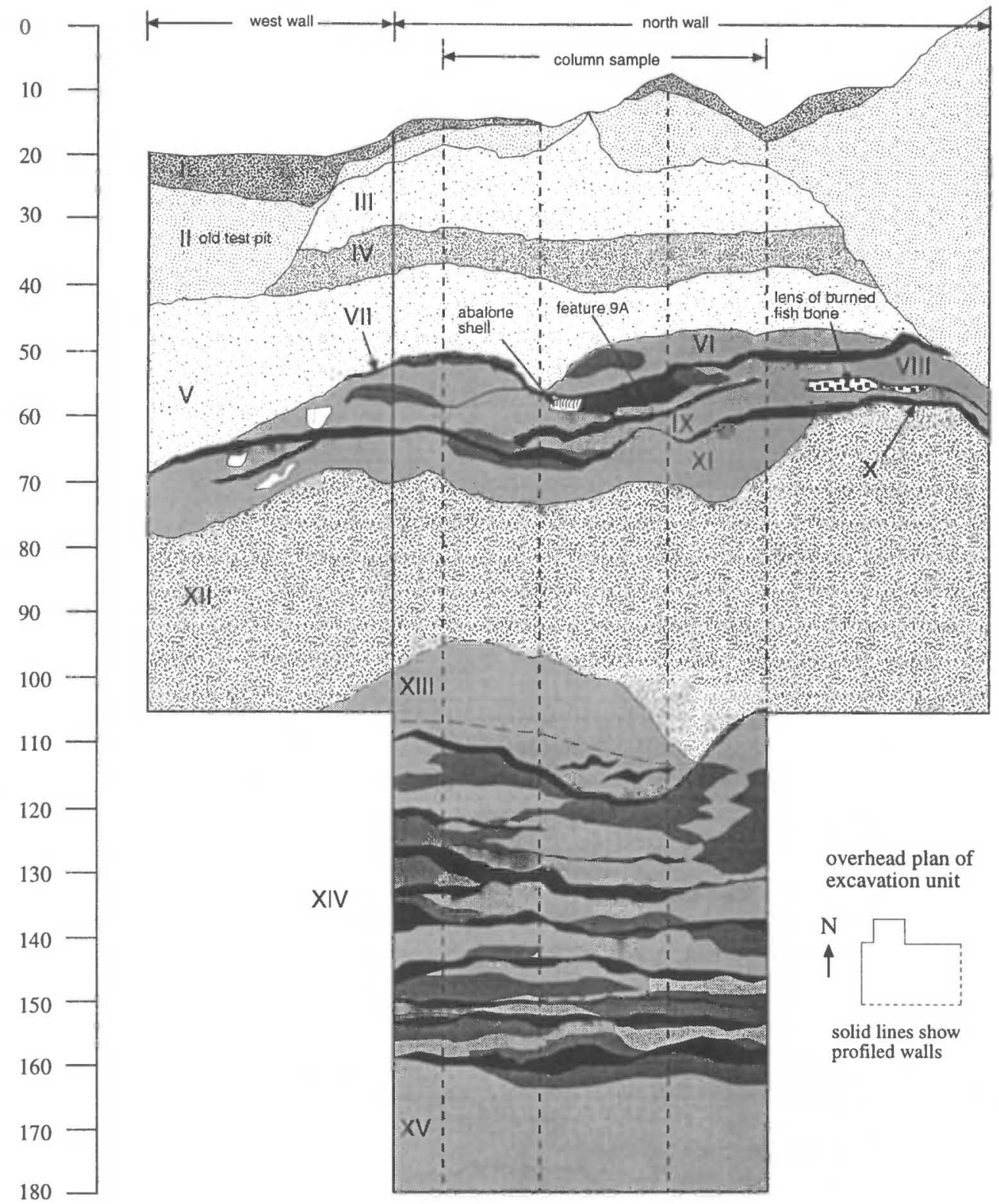

Fig. 4. Stratigraphy of test sounding in the middle chamber of Daisy Cave (CA-SMI-261A)

\section{Terminal Pleistocene Series}

CAMS-9094. Column E-6, Stratum G

Small twig fragment from same general provenience as Beta-14660 and Beta-52360, although shell is found primarily in the upper portions of the $4-6 \mathrm{~cm}$ thick Stratum $\mathrm{G}$ and materials from the 
lower part of $\mathrm{G}$ were not differentiated during excavation. Collected 1985 by Guthrie and Snethkamp, submitted 1993 by Erlandson to test the accuracy of marine shell dates from same stratum.

Comment (J.E.): overall, this date fits well within the depositional chronology for Daisy Cave. After calibration this date, with a midpoint of $c a .12,290 \mathrm{cal} \mathrm{BP}$, appears to be slightly older than shells from the same stratum. While the twig may have come from the lower portions of Stratum G, other evidence suggests that marine upwelling (and the regional reservoir effect) may have been less intense at this time, increasing the apparent disparity between the three dates from this stratum (Kennett et al. 1996).

Beta-52360. Column E-6, Stratum G

Black turban (Tegula funebralis) shell fragments (13.2 g), broken and carefully cleaned of all adhering sediment, from the lowest shell midden stratum in Column E-6. Collected 1986 by Guthrie and Snethkamp, submitted 1992 by Erlandson and Snethkamp to check validity of Beta-14660.

Comment (J.E.): this date independently confirmed, based on the analysis of shell from a second gastropod species, that shell in Stratum $G$ was deposited during the terminal Pleistocene. A >1000 yr gap between the deposition of shell at the base of Stratum F and the shells in Stratum G also suggests that displacement of shell or artifacts from above has not occurred.

Beta-14660. Column E-6, Stratum G

$10,700 \pm 90$

Red abalone shell $(>100 \mathrm{~g})$ from $110 \mathrm{~cm}$ below surface, at the base of shell-bearing deposits exposed in the north wall of Rozaire's test unit E-5, located along the dripline of the rockshelter. Collected 1985 by Guthrie and Snethkamp, submitted 1985 by Guthrie to establish the age of earliest apparent human occupation of the cave.

Comment (J.E.): this date first documented a very early human occupation of Daisy Cave and the presence of humans on the Northern Channel Islands at $c a .11,700 \mathrm{cal}$ BP. The cultural origin of this abalone shell has been questioned (Erlandson 1991, 1994: 194), but subsequent work suggests that an ephemeral human occupation of Daisy Cave did take place during the terminal Pleistocene (Erlandson 1993; Erlandson et al. 1996b).

CAMS-9096. Column E-6, Stratum I

$11,180 \pm 130$

Small carbonized twig fragment from a dark brown cave soil below shell midden. Retrieved from flotation of sediments from column sample. Collected 1985 by Guthrie and Snethkamp, submitted 1993 by Erlandson to extend chronology of paleontological sediments underlying the archaeological strata.

Comment (J.E.): preliminary analysis of pollen from Stratum I suggests that pine trees were abundant in the cave vicinity at this time (West and Erlandson 1994).

CAMS-14369. Column E-6, Stratum J

Small carbonized twig fragment from thin cave soil below shell midden, retrieved from flotation of sediments from Column E-6. Collected 1985 by Guthrie and Snethkamp, submitted 1993 by Erlandson to extend chronology of paleontological strata at Daisy Cave.

Comment (J.E.): this date indicates that the base of the 1985 excavations terminated in levels equal to $c a$. $13,640 \pm 120 \mathrm{cal} \mathrm{BP}$. Pollen from this stratum also suggests that a pine forest existed in the cave vicinity at this time (West and Erlandson 1994). 
Chunks of wood charcoal $(16.0 \mathrm{~g})$, apparently from sizeable branches or logs, from the lowest of several dark charcoal-rich lenses located between 110 and $160 \mathrm{~cm}$ below the floor of the middle chamber of Cave A. Collected 1994 by Tveskov and Erlandson, submitted 1994 by Erlandson and Morris.

Comment (J.E.): the potential for an "old wood" problem was anticipated on submission of this sample, but the antiquity of this date was still unexpected. In the field these dark lenses, overlain by 30 $50 \mathrm{~cm}$ of light brown sterile silt capped by an Early Holocene shell midden, were considered to be possible hearth features. They contain burned rock, welded sediments, burned bone, occasional wood fragments, and rare cultural artifacts. A large Monterey chert flake of unquestionable cultural origin was found in situ within the uppermost (undated) dark lens in Stratum XIV. A small chert flake was found in screen residuals from Stratum XIV, but its provenience is much less certain.

\section{DISCUSSION AND CONCLUSIONS}

Our chronological studies at Daisy Cave provide a detailed temporal framework for understanding environmental changes on the Northern Channel Islands and the southern California coast over the past 13,000 to 19,000 calendar yr. Pollen samples from the lower levels of Daisy Cave suggest, for instance, that prior to $c a .12,000 \mathrm{cal} \mathrm{BP}$ a pine forest grew outside the cave, probably covering a more extensive coastal plain exposed by lower sea levels (West and Erlandson 1994). The bathymetry off Daisy Cave is relatively steep, however, and even 12,000 yr ago this coastal plain was probably not more than several hundred meters wide. The presence of small relict stands of Bishop pine (Pinus muricata) and Torrey pine (P. torreyana) on the other Northern Channel Islands, and the recovery of a pine needle from Stratum $G$ tentatively identified as $P$. muricata, suggest that this forest may have consisted of one or both of these species. The pollen spectra take on a more modern character after $c a .12,000 \mathrm{yr}$ ago, when the percentage of pine pollen declines dramatically and Compositae, Rosaceae and Quercus (oak) pollen all increase significantly.

A comprehensive analysis of recently collected faunal remains from Daisy Cave has yet to be completed and contextual problems make it difficult to determine the age of many specimens excavated prior to the 1980s. Nonetheless, the remains of several species locally or regionally extinct have been found at Daisy Cave. Walker (1980) identified the remains of a relatively large deer mouse (Peromyscus nesodytes) in the lower levels of the cave, a species later replaced by a diminutive mainland cousin (P. maniculatus). Walker also identified the remains of the western spotted skunk (Spilogale gracilis) and an ornate shrew (Sorex ornatus), neither of which is present on San Miguel Island today. Guthrie (1980) identified the remains of an extinct vampire bat (Desmodus stocki), and an extinct flightless scoter (Chendytes lawi). Guthrie (1980: 695) also identified relatively large numbers of the bones of two sea birds that no longer breed on the island, the manx shearwater (Puffinus puffinus) and Leach's storm petrel (Oceanodroma leucorhoa), suggesting that they may have bred on the island in the past. Faunal remains from the shell midden strata also suggest that rocky intertidal habitats were productive throughout much of the past 10,000 yr. This contradicts some general claims (e.g., Yesner 1987) that coastal habitats only became productive for human foragers to exploit when sea level stabilized during the Middle Holocene. Fish bones are relatively common in all the Holocene midden levels, and sea mammal and sea bird remains also are present.

Since at least $11,600 \mathrm{cal} \mathrm{BP}$, the environmental record at Daisy Cave is accompanied by well-preserved shell midden deposits that document the adaptations of maritime peoples to the Santa Barbara Channel environment. Those shell midden deposits contain the remains of hundreds of animal 
and plant species interspersed with other animal and plant remains deposited naturally as paleontological deposits. The available data suggest that Daisy Cave was occupied by humans primarily during five periods: an ephemeral episode of site use ca. 11,600 \pm 150 cal BP; repeated occupations between $c a .8500$ and $10,000 \mathrm{cal} \mathrm{BP}$; a relatively brief episode $c a .6700 \pm 200 \mathrm{cal} \mathrm{BP}$; more intensive occupation(s) dating to $c a .3200 \pm 200 \mathrm{cal} \mathrm{BP}$; and one or more episodes $c a .700 \pm 200 \mathrm{cal} \mathrm{BP}$. The most poorly dated portion of this archaeological chronology is the younger end of the spectrum, because most of these deposits were excavated during the 1960s (Rozaire 1978) or have been eroded away. Additional occupational components may be discovered, however, with further dating of LACMNH collections.

Artifacts, ecofacts and features at Daisy Cave provide a wealth of information about human adaptations to the island and marine habitats and fluctuations in Channel Island environments through time. With the chronological and other analyses completed to date, several preliminary conclusions can be made about the environmental and archaeological records at Daisy Cave.

First, pine forest habitats appear to have been present on San Miguel Island-and probably were much more widespread in the Santa Barbara Channel area-until between 12,000 and 13,000 cal BP, when the frequency and percentages of pine pollen deposited at Daisy Cave decline dramatically. This is consistent with Axelrod's (1967: 110) suggestion that "an essentially continuous closed-cone pine forest blanketed the outer coast and islands during the late Pleistocene, and as recently as 14,500 to 12,000 years ago". It is also consistent with Heusser's (1978) pollen spectrum for the Santa Barbara Basin, in which the contribution of pine pollen decreases from $\mathrm{ca} .40 \%$ to less than $20 \%$ in sediments dated to $c a$. $12,000 \pm 500 \mathrm{cal} \mathrm{BP}$. These vegetation changes are closely linked to postglacial warming, which also led to dramatic sea level rise and the breakup of Santarosae into its modern constituent islands. This marine transgression also shifted the coastline progressively closer to Daisy Cave during the terminal Pleistocene and the Holocene. By the Late Holocene, it appears that the environment of the Daisy Cave area had taken on an essentially modern character.

Data from Daisy Cave suggest that the Northern Channel Islands were settled by humans by at least 11,600 cal BP, a colonization that required relatively seaworthy watercraft and a substantial economic reliance on marine resources. Archaeological remains from the terminal Pleistocene cave occupation are limited because only small samples of these basal deposits have been excavated to date. Based on the available data, however, we attribute this occupation to maritime Paleoindian or "Paleocoastal" peoples (see Moratto 1984). This occupation appears to be as much as 1000 to 1500 yr earlier than several mainland Paleocoastal sites from the southern California coast, which are dated between $c a .9500$ and 10,000 cal BP (Erlandson 1994). Thus, the terminal Pleistocene component at Daisy Cave currently represents the earliest known Paleocoastal occupation on the California coast. Currently, it seems most likely that these early maritime peoples were descended from even earlier Paleoindian peoples who appear to have left Clovis-like fluted points on the southern California coast (see Erlandson, Cooley and Carrico 1987) a millennium or more prior to the initial occupation of Daisy Cave. Nonetheless, the data from Daisy Cave provide additional evidence for the relatively early diversification of Paleoindian economies in western North America.

During the Early Holocene, Daisy Cave was occupied repeatedly by maritime peoples who relied heavily on marine resources like shellfish, fish and sea mammals. Preliminary dietary reconstructions suggest that fish made a significant contribution to the diet, at least while these people occupied Daisy Cave. Technological data support this assertion, as one of the most common types of finished artifact found in the Early Holocene levels is the small bone gorge, a straight bipointed hook. This contrasts with Early Holocene sites from the adjacent southern California mainland coast, 
where fish bone and fishing tackle are relatively rare, and fishing seems to have played a much more supplemental subsistence role (Erlandson 1994: 263). By 8500 to $9000 \mathrm{cal} \mathrm{BP}$, grinding stones (manos and metates) also make up a prominent part of many mainland artifact assemblages, suggesting that small seeds and other plant foods were important staples. At Daisy Cave, no unequivocal milling tools have been found in the lower archaeological levels. This is consistent with findings from other Early Holocene island sites and seems to be related to the relatively low diversity and productivity of edible seed-producing plants on the Channel Islands. Presently, Daisy Cave provides the only direct evidence for the types of basketry and other woven artifacts used by Early Holocene peoples along the Pacific Coast of North America (Connolly, Erlandson and Norris 1995).

Due to the limited amounts of cultural occupation and natural sedimentation that took place at Daisy Cave during the Middle Holocene, we know much less about the nature of cultural and environmental changes during this period. By the Late Holocene, however, Daisy Cave is once again the scene of relatively intensive and repeated human occupation. A detailed picture of Late Holocene cultural changes has yet to emerge from the site, but we suspect it is during this period that much of the cultural complexity and artistic elaboration typical of the ethnographic Chumash developed. At Daisy Cave, the evidence for these developments is seen in the presence of a fully diversified material culture that includes circular shell fish hooks, a wide range of beads and ornaments, a bird bone panpipe, a fragment of a redwood plank boat (tomol), asphaltum coated baskets and tarring pebbles, the bead-maker's kit containing standardized microblade drills and bead refuse typical of Chumash craft production, and a symmetrical and highly finished stone pestle. Although the archaeological record at Daisy Cave provides only a series of snapshots in time, the appearance of this elaborate and sophisticated Chumash material culture seems to be the culmination of over 11,000 $\mathrm{yr}$ in the evolution of local maritime societies.

Finally, on a more methodological note, the Daisy Cave chronology is marked by the relatively close correlation of ${ }^{14} \mathrm{C}$ dates on marine shell and charcoal samples. Scientists working on the California coast have relied heavily on the dating of marine shells for decades, but there remains a pervasive oral history about the unsuitability of marine shell for ${ }^{14} \mathrm{C}$ dating. Considering the numerous uncertainties and errors associated with comparing dates run by different laboratories on samples derived from different carbon reservoirs, our results provide a remarkably consistent chronology for the paleontological and archaeological deposits at Daisy Cave. In part, this is due to the finely stratified nature of the Daisy Cave deposits, the extremely good preservation of faunal and botanical remains at the site, the meticulous procedures used in recent excavations of the site, and the careful selection and pretreatment of ${ }^{14} \mathrm{C}$ samples to avoid problems associated with contamination, the old wood effect, etc. Nonetheless, our study clearly demonstrates that marine shell samples can provide relatively high-resolution ${ }^{14} \mathrm{C}$ dates for the construction of archaeological and paleontological chronologies. This is true despite the tentative identification of temporal fluctuations in upwelling and the regional reservoir effect for the Santa Barbara Channel region, based largely on the analysis of shell and charcoal samples from Daisy Cave (Kennett et al. 1996).

\section{ACKNOWLEDGMENTS}

We are grateful to Charles Rozaire and Pandora Snethkamp, who graciously shared information about their work at Daisy Cave. We also thank Jerry Stipp, Murry Tamers and the staff of Beta Analytic for their technical expertise in analyzing ${ }^{14} \mathrm{C}$ samples from Daisy Cave, and John Southon and Michaele Kashgarian for technical assistance at CAMS, Lawrence Livermore National Laboratory. Figures 3 and 4 were drafted by Mark Tveskov, while Figures 1 and 2 were adapted from originals produced by Thomas Connolly and Susan Hammersmith, respectively. Our research has been sup- 
ported by Channel Islands National Park, the Southwest Parks and Monuments Association, the University of Oregon, the University of California and the Claremont Colleges. Guy Prouty (University of Oregon) tentatively identified a pine needle from Stratum G. Finally, thanks to Michael Schiffer, Austin Long, David Sewell and Renee Kra for comments and editorial assistance that substantially improved this manuscript.

\section{REFERENCES}

Arnold, J. E. 1987 Craft Specialization in the Prehistoric Channel Islands, California. Berkeley, University of California Publications in Anthropology 18: 278 p.

1992 Complex hunter-gatherer-fishers of prehistoric California: Chiefs, specialists, and maritime adaptations of the Channel Islands. American Antiquity 57: 60-84.

Axelrod, D. I. 1967 Evolution of the Californian closedcone pine forest. In Philbrick, R. N., ed., Proceedings of the Symposium on the Biology of the California Islands. Santa Barbara, Santa Barbara Botanic Garden: 93-149.

Connolly, T. J., Erlandson, J. M. and Norris, S. E. 1995 Early Holocene basketry and cordage from Daisy Cave, San Miguel Island, California. American Antiquity 60: 309-318.

Daly, M. 1990 Mrs. Waters' diary of her life on San Miguel Island, January 1-June 27, 1888. In Daly, M, ed., A Step Back in Time: Unpublished Channel Islands Diaries. Santa Barbara, Santa Cruz Island Foundation Occasional Papers 4: 5-51.

Davis, J. C., Proctor, I. D., Southon, J. R., Caffee, M. W., Heikkinen, D. W., Roberts, M. L., Moore, T. L., Turteltaub, K. W., Nelson, D. E., Loyd, D. H., Vogel, J. S.1990 LLNL/UC AMS facility and research program. Proceedings of the 5th International Conference on Accelerator Mass Spectrometry. Nuclear Methods in Physics Research B52(3-4): 269-272.

Erlandson, J. 1991 Early maritime adaptations on the Northern Channel Islands, California. In Erlandson, J. M. and Colten, R. H., eds., Hunter-Gatherers of Early Holocene Coastal California. Perspectives in California Archaeology 1. Los Angeles, Institute of Archaeology, University of California: 101-111.

1993 Evidence for a terminal Pleistocene human occupation of Daisy Cave, San Miguel Island, California. Current Research in the Pleistocene 10: 17-21.

1994 Early Hunter-Gatherers of the California Coast. New York, Plenum: 336 p.

Erlandson, J. M., Cooley, T. and Carrico, R. 1987 A fluted projectile point fragment from the southern $\mathrm{Cal}$ ifornia coast: Chronology and context at CA-SBA1951. Journal of California and Great Basin Anthropology 9: 120-128.

Erlandson, J. M., Kennett, D. J., Behl, R. and Hough, I. 1996a The Cico chert source on San Miguel Island, California. Journal of California and Great Basin Anthropology, in press.
Erlandson, J., Tveskov, M., Kennett, D. and Ingram, L. 1996b Further evidence for a terminal Pleistocene occupation of Daisy Cave, San Miguel Island, California. Current Research in the Pleistocene, in press.

Forgeng, E. E. (ms.) 1992 Archaeology, ecology and siteformation processes at the Daisy Cave midden, San Miguel Island, California. Masters paper, Department of Anthropology, University of Oregon.

Glidden, R. (ms.) 1919 San Miguel Island: May 6th 1919 to October 4th, 1919. Avalon, California: Catalina Museum: 4 p.

Guthrie, D. A. 1980 Analysis of avifaunal and bat remains from midden sites on San Miguel Island. In Power, D. M., ed., The California Islands: Proceedings of a Multidisciplinary Symposium. Santa Barbara, Santa Barbara Museum of Natural History: 689-702. 1993 Listen to the birds? The use of avian remains in Channel Islands archaeology. In Glassow, M. A., ed., Archaeology on the Northern Channel Islands of California: Studies of Subsistence, Economics, and Social Organization. Salinas, California, Coyote Press Archives of California Prehistory 34: 153-167.

Heusser, L. E. 1978 Pollen in Santa Barbara Basin, California: A 12,000 year record. Geological Society of America Bulletin 89: 673-678.

Heye, G. C. 1921 Certain Artifacts from San Miguel Island. Museum of the American Indian Notes and Monographs 7(4). New York, Heye Foundation: 211 p.

Johnson, D. L. 1972 Landscape Evolution on San Miguel Island, California. Ph.D. dissertation, University of Kansas. Ann Arbor, University Microfilms International: $391 \mathrm{p}$.

Kennett, D. J., Ingram, B. L., Erlandson, J. M. and Walker P. 1996 Evidence for temporal fluctuations in marine radiocarbon reservoir ages in the Santa Barbara Channel, southern California. Journal of Archaeological Science, in press.

Moratto, M. J. 1984 California Archaeology. Orlando, Academic Press: 757 p.

Orr, P. C. 1950 On San Miguel Island. Museum Talk [Santa Barbara Museum of Natural History] 25(2): 13-18.

1968 Prehistory of Santa Rosa Island. Santa Barbara, Santa Barbara Museum of Natural History: 253 p.

Rozaire, C. E. (ms.) 1978 Archaeological Investigations on San Miguel Island, California. Los Angeles, Los 
Angeles County Museum of Natural History: 228 p. Rozaire, C. E. 1993 The bladelet industry on Anacapa and San Miguel Islands, California. In Glassow, $M$. A., ed., Archaeology on the Northern Channel Islands of California. Salinas, California, Coyote Press Archives of California Prehistory 34: 63-74.

Schiffer, M. B. 1986 Radiocarbon dating and the "old wood" problem: The case of the Hohokam chronology. Journal of Archaeological Science 13: 13-30.

Stuiver, M. and Reimer, P. 1993 Extended ${ }^{14} \mathrm{C}$ data base and revised CALIB $3.0{ }^{14} \mathrm{C}$ age calibration program. Radiocarbon 35(1): 215-230.

Vogel, J. S., Nelson, D. E. and Southon, J. R. $1987{ }^{14} \mathrm{C}$ background levels in an accelerator mass spectrometry system. Radiocarbon 29(3): 323-333.

Walker, P. L. 1980 Archaeological evidence for the extinction of three terrestrial mammals on San Miguel Island. In Power, D. M., ed., The California Islands:
Proceedings of a Multidisciplinary Symposium. Santa Barbara, Santa Barbara Museum of Natural History: 703-717.

Walker, P., Craig, S., Guthrie, D. and Moore, R. (ms.) 1978 An ethnozoological analysis of faunal remains from four Santa Barbara Channel Island archaeological sites. Santa Barbara: Department of Anthropology, University of California.

West, G. J. and Erlandson, J. M. 1994 A Late Pleistocene pollen record from San Miguel Island, California: Preliminary results. American Quaternary Association Program and Abstracts. 13th biennial meeting, Minneapolis: 256.

Yesner, D. R. 1987 Life in the "Garden of Eden": Causes and consequences of the adoption of marine diets by human societies. In Harris, M. and Ross, E. B., eds., Food and Evolution. Philadelphia, Temple University Press: 285-310. 